\title{
Multiple neuroendocrine tumors of the small bowel: A case report
}

\author{
Selene Rossi ${ }^{1, *}$, Federico Farinacci ${ }^{2}$, Alessandro Gemini ${ }^{2}$, Felice Mucilli ${ }^{1}$
}

${ }^{1}$ Department of General and Thoracic Surgery, University Hospital of Chieti, Chieti, Italy.

${ }^{2}$ Department of Digestive Surgery, St. Mary's Hospital, Terni, Italy

\section{To Cite}

Rossi S, Farinacci F, Gemini A, Mucilli F, Multiple neuroendocrine tumors of the small bowel: a case report. J Gastric Surg 2020; 2(1) $22-23$

\section{Pubblication history}

Received: January 27, 2020

Accepted: February 14, 2020

Article impress: February 15, 2020

Published on line: February 16, 2020

\section{*Correspondence to}

Dr. Selene Rossi

Department of General and Thoracic Surgery, University Hospital of Chieti, Chieti 66100, Italy

sele.rossi@gmail.com

\begin{abstract}
Neuroendocrine tumors of the small bowel are rare malignancies that often occur in the case of bowel obstruction or intestinal bleeding. The present case is a 46-year-old man who underwent emergency surgery for obstruction due to a rare presentation of multiple neuroendocrine lesions located in an intestinal loop. Pathology showed 15 NETs (grade 1) between 4 and $15 \mathrm{~mm}$ diameter with positive lymph nodes and liver metastases already detected by the preoperative CT scan.
\end{abstract}

Key words:

neuroendocrine tumor, NETs, small bowel. 


\section{Background:}

Primary small bowel malignant tumors represent only $1-2 \%$ of all gastrointestinal neoplasms. Neuroendocrine tumors (NET) are classified as a rare subgroup of malignant diseases, although they are the second most common malignant tumors of the small bowel after adenocarcinoma. $[1,2]$

These tumors are asymptomatic for a long time, or they occur with gastrointestinal bleeding, carcinoid syndrome, abdominal pain or bowel obstruction; thus, their diagnosis is often challenging.[3]

\section{Case Report:}

Our patient is a 46-year-old man admitted for abdominal pain and intestinal obstruction.

Diabetes and hypertension are reflected in his case history. A CT scan of the abdomen revealed a small bowel stenosis of about $4 \mathrm{~cm}$ in its proximal tract associated with intussusception, multiple metastases in the liver and lymph nodes. The radiologist suspected a neuroendocrine tumor of the ileum due to the typical hypervascularization of these metastases.

During surgery, multiple intestinal nodules were detected, and a small bowel resection was performed (67 $\mathrm{cm}$ in length, Figure 1).

The pathology report showed multiple NET lesions (15 tumors, diameter between 4 and $15 \mathrm{~mm}$, grade 1, Figure 2). Metastases were found in 11 of the 34 total analyzed lymph nodes.

The patient underwent adjuvant oncological treatment.

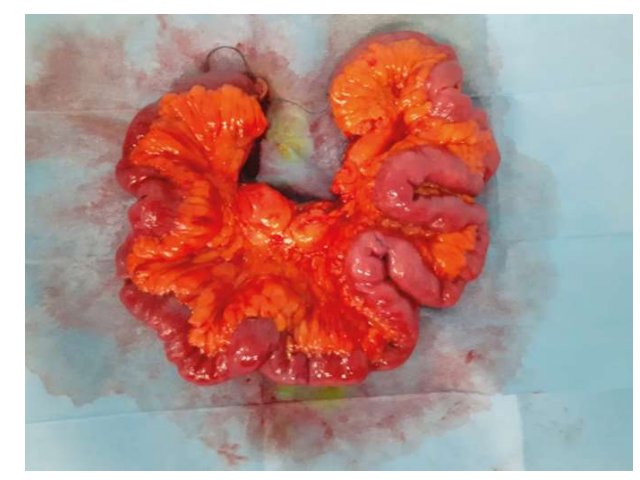

Figure 1: View of the surgical specimen

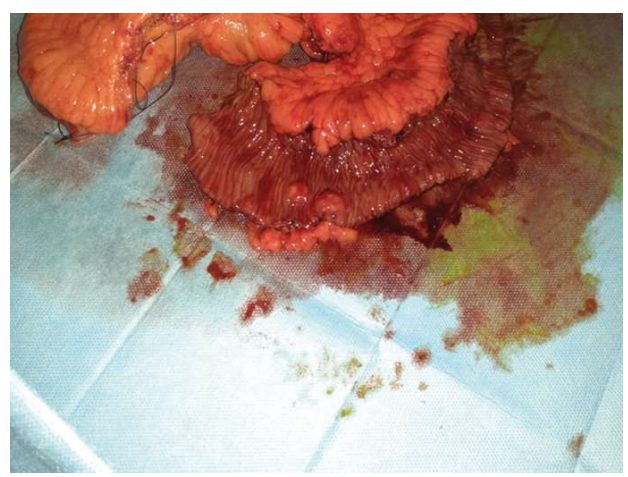

Figure 2: Internal view of the small bowel showing multiple NETs

\section{Discussion:}

NETs of the small bowel commonly occur as a surgical emergency with symptoms of obstruction and intussusception as in the present case.

Moreover, according to international guidelines, surgical treatment is recommended in the case of multiple intestinal NET lesions[4]. Multiple tumors are found in up to $40 \%$ of cases[5], and even small tumors under $1 \mathrm{~cm}$ may show early lymph node metastases.

NETs larger than $2 \mathrm{~cm}$ have an increased risk of metastases in the lymph nodes and liver with a probability of $80 \%$ and $20 \%$, respectively[6]. Carcinoid syndrome, which occurs in $20-30 \%$ of patients with NETs, is often (95\%) associated with the presence of liver metastases[4].

In our case, the CT scan suggested the type of disease through the typical metastases' characteristics. The final diagnosis was only possible after surgical exploration and subsequent pathological analysis.

In our patient, the diameter of the lesions detected was between 0.4 and $1.5 \mathrm{~cm}$, without carcinoid syndrome but with liver and lymph node metastases. In cases with distant metastases, the decision of whether to resect the primary tumor or not is based on the following considerations[4]:

1. Achieving R0 resection including the primary tumor and distant metastases (curative intent).

2. In patients with symptoms due to intestinal obstruction or bleeding, palliative resection of the primary tumor is mandatory as a life-saving treatment. Moreover, mesenteric pathological lymph nodes should be removed as completely as possible to avoid occlusion of vessels with consequent intestinal ischemia.

3. Non-curative primary tumor resection in metastatic disease seems to improve overall survival and therefore may be considered. This evidence is shown in a recent systematic review of the literature that analyzed data from six comparative observational studies[7].

The prognosis for patients with NETs depends on both disease staging and grading. Jann et al.[8] reported a 5 -year tumor-specific survival rate for small bowel NETs of $100 \%$ for stages I and II, $97.1 \%$ for stage III and $84.8 \%$ for stage IV.

\section{References}

[1] Zonca P, Peteja M, Richter V, Vavra P, Ihnat P. [Primary malignant small bowel tumors]. Rozhl Chir.95:344-9.

[2] Nemec L, Fabian P, Tomasek J, Jarkovsky J, Sefr R, Fiala L. [Malignant tumors of the small bowel]. Rozhl Chir.96:252-9.

[3] Scherubl H, Jensen RT, Cadiot G, Stolzel U, Kloppel G. Neuroendocrine tumors of the small bowels are on the rise: Early aspects and management. World J Gastrointest Endosc. 2010;2:325-34

[4] Niederle B, Pape UF, Costa F, Gross D, Kelestimur F, Knigge U, et al. ENETS Consensus Guidelines Update for Neuroendocrine Neoplasms of the Jejunum and Ileum. Neuroendocrinology. 2016;103:125-38.

[5] Xavier S, Rosa B, Cotter J. Small bowel neuroendocrine tumors: From pathophysiology to clinical approach. World J Gastrointest Pathophysiol. 2016;7:117-24.

[6] Johanssen S, Boivin M, Lochs H, Voderholzer W. The yield of wireless capsule endoscopy in the detection of neuroendocrine tumors in comparison with CT enteroclysis. Gastrointest Endosc. 2006;63:6605.

[7] Capurso G, Rinzivillo M, Bettini R, Boninsegna L, Delle Fave G, Falconi M. Systematic review of resection of primary midgut carcinoid tumour in patients with unresectable liver metastases. Br J Surg. 2012;99:1480-6.

[8] Jann H, Roll S, Couvelard A, Hentic O, Pavel M, Muller-Nordhorn J, et al. Neuroendocrine tumors of midgut and hindgut origin: tumornode-metastasis classification determines clinical outcome. Cancer. 2011;117:3332-41. 